\title{
QUANTITATIVE EVIDENCE FOR COCHLEAR, NON-NEURONAL NOREPINEPHRINE *
}

\author{
KYLE E. RAREY ${ }^{1}$, MURIEL D. ROSS ${ }^{1}$ and CHARLES B. SMITH ${ }^{2}$ \\ Departments of ${ }^{1}$ Anatomy and ${ }^{2}$ Pharmacology, University of Michigan, Ann Arbor, \\ MI 48109, U.S.A.
}

(Received 18 September 1980; accepted 24 March 1981)

Endogenous norepinephrine was quantitatively measured in cochlear tissues of pigmented and nonpigmented animals by high-performance liquid chromatography and electrochemical detection. Epinephrine, dopamine and serotonin were not detected. The cochlear norepinephrine content of the pigmented animals was found to be more than double that present in corresponding albinos. Cochlear norepinephrine was only minimally depleted $48 \mathrm{~h}$ after surgical removal of the superior cervical ganglion. $12 \mathrm{~h}$ after administration of reserpine $(5 \mathrm{mg} / \mathrm{kg})$, cochlear norepinephrine was partially depleted. These results indicate that the norepinephrine located in the cochlea is probably not confined entirely to noradrenergic nerve terminals.

Key words: norepinephrine; cochlea; melanin; melanocytes.

\section{INTRODUCTION}

Catecholamines have been found in the inner ear of many different species $[4,15-17$, 20-23,26]. By fluorescence and electron microscopy, fluorescing nerve fibers, assumed to contain stores of norepinephrine, and vesicles typical of those found in noradrenergic neurons have been demonstrated almost entirely in the modiolar and habenular regions of the cochlea $[4,15-17,20-23,26]$. Only in the case of the guinea pig have noradrenergic nerve fibers been reported to occur more laterally near the vas spirale $[7,23]$.

Nerve fibers which have the fluorescent characteristics of noradrenergic neurons disappear or are decreased markedly in number after superior cervical ganglionectomy or after the administration of reserpine [15,20,22,23]. Because extirpation of the superior cervical ganglion was considered to ablate noradrenergic fibers which distribute to the cochlea and reserpine was thought to deplete norepinephrine stores from noradrenergic nerves, cochlear norepinephrine was assumed to be located within postganglionic noradrenergic nerves $[15,20,22,23]$. The possibility that some cochlear norepinephrine is located outside of noradrenergic neurons was suggested by Hilding $[8,9]$ who reported the presence of chromaffin granules in spiral ligament cells near the stria vascularis. He used the potassium dichromate stain reaction and electron microscopy to identify these

\footnotetext{
* This work was presented in part at the meeting of the American Association of Anatomists, Omaha, Nebr. 26 April-1 May 1980.
} 
cells. The presence of cochlear chromaffin cells has not been confirmed. Several investigators have suggested that melanocytes, which are distributed throughout cochlear tissues including the lateral cochlear wall, might contain a vasoactive substance such as norepinephrine $[1,18]$. This hypothesis is based upon the observations that these cells are located in close approximation to blood vessels and that they contain melanin, a substance which is chemically related to catecholamines.

The objectives of this study were to identify and quantitatively measure endogenous, biogenic amines present in the cochlear tissues of pigmented and non-pigmented animals by high-performance liquid chromatography and electrochemical detection, and to determine whether such amines are confined entirely to cochlear noradrenergic nerves. Pigmented and non-pigmented animals were compared because of the difference in the melanin content of cochlear melanocytes. In contrast to previous techniques utilized, the present technique provides two distinct advantages. First, high-performance liquid chromatography and electrochemical detection can distinguish conclusively between norepinephrine, epinephrine, dopamine and serotonin. Second, this technique can measure quantitatively picogram quantities of biogenic amines in a single sample. [12].

\section{MATERIALS AND METHODS}

\section{Small preparations}

Cochleas were collected from eleven Sprague-Dawley albino rats, twelve hooded rats, eight Hartley albino guinea pigs, eight pigmented guinea pigs, and six pigmented cats. All animals were adult males. After decapitation, the bony labyrinths were dissected from the temporal bones and transferred to cold $5 \mathrm{mM}$ Tris-HCl buffer $(\mathrm{pH} 7.4)$. With the aid of a dissecting microscope, the capsular shell of each cochlea was removed, and a transverse cut was made through the base of the modiolus. Cochlear tissues which included the lateral cochlear wall, organ of Corti, modiolus and intramodiolar tissues were removed from 2-3 animals and pooled for each experimental sample. Tissues were weighed and placed in homogenizing tubes that contained $0.2-0.5 \mathrm{ml}$ of $0.05 \mathrm{M} \mathrm{HClO}_{4}$ to which dihydroxybenzylamine (internal standard) had been added. After homogenization and centrifugation of each sample, 20-25 $\mu$ l of supernatant were injected directly into the highperformance liquid chromatography system that was coupled to the electrochemical detector.

To determine whether norepinephrine was confined totally to cochlear adrenergic nerve terminals, superior cervical ganglionectomies were performed under ether anesthesia on nine albino rats $48 \mathrm{~h}$ prior to killing, and reserpine $(5 \mathrm{mg} / \mathrm{kg})$ was administered i.p. to nine albino rats $12 \mathrm{~h}$ prior to killing. At the time of killing, cochlear tissues of the treated rats were collected, pooled and prepared as described above.

\section{Reagents}

Reagent grade chemicals utilized were: 3,4-dihydroxybenzylamine hydrobromide (Aldrich); l-norepinephrine bitartrate hydrate (Calbiochem); dopamine hydrochloride (Aldrich); serotonin creatinine sulfate (Calbiochem); l-epinephrine bitartrate (Sigma) and sodium octyl sulfate (Eastman Kodak).

The column eluant was a citrate buffer which consisted of the following: citric acid, 
$0.06 \mathrm{M} ; \mathrm{Na}_{2} \mathrm{HPO}_{4}, 0.04 \mathrm{M}$; and sodium octyl sulfate, $0.3 \mathrm{mM}$ (as described by Felice et al. [5]. Eluant was prepared daily.

\section{Instrumentation}

The high-performance liquid chromatography system was composed of a Waters (Model 6000A) high-performance pump, a Waters (Model U6K) Universal injector and a reverse-phase $\mu$ Bondapak $C_{18}$ column $(30 \mathrm{~cm} \times 3.9 \mathrm{~mm}$ i.d.). Biogenic amines were detected by a Bioanalytical electrochemical detector, Model LC-10. The potential of the detector electrode was set at $+0.72 \mathrm{~V}$ vs. $\mathrm{Ag} / \mathrm{AgCl}$ reference electrode. The flow-rate of the eluant was $0.8 \mathrm{ml} / \mathrm{min}$. The recorder was set at $30 \mathrm{~cm} / \mathrm{h}$.

\section{Calculations}

By utilizing the ratio of the recorded height of the norepinephrine peak to the peak height of the dihydroxybenzylamine (internal standard) the quantity of norepinephrine in each sample was extrapolated from a standard curve. A standard curve was prepared by eluting known concentrations of biogenic amines and comparing their peak heights to that of dihydroxybenzylamine. A representative chromatogram of catecholamines of known concentrations that was used for a standardization curve is illustrated in Fig. 1. All

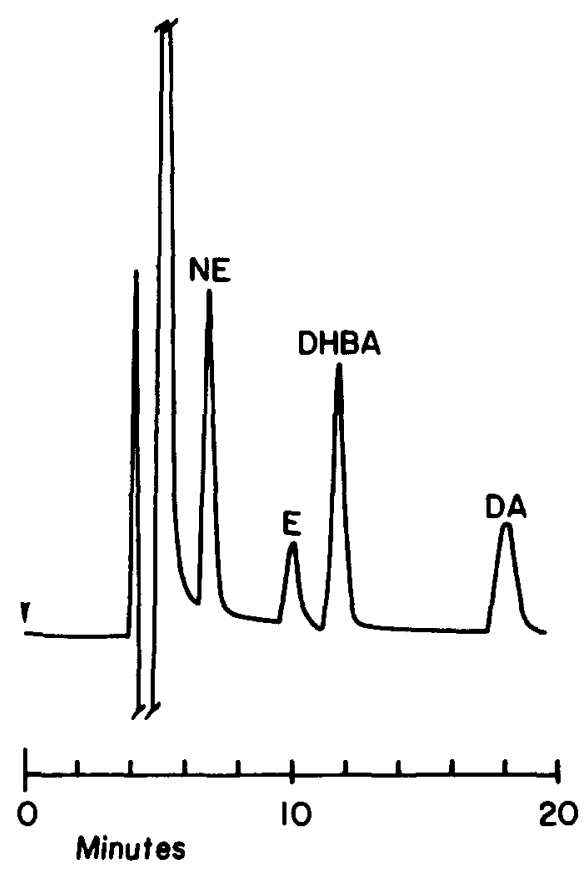

Fig. 1. Chromatogram of catecholamine standards. The chromatographic conditions were: A, stationary phase, $30 \mathrm{~cm} \times 3.9 \mathrm{~mm}$ i.d. $\mu$ Bondapak $\mathrm{C}_{18}$ (Waters Assoc.); $\mathrm{B}$, mobile phase, citric acid/phosphate eluant as described in the text; $C$, flow rate, $0.8 \mathrm{ml} / \mathrm{min} ; \mathrm{D}$, temperature, ambient; $\mathrm{E}$, amount injected; $10 \mu \mathrm{l}$ of a $0.05 \mathrm{M} \mathrm{HClO}_{4}$ solution, containing $1 \mathrm{ng}$ of norepinephrine (NE), epinephrine (E), dopamine (DA) and $2.5 \mathrm{ng}$ of dihydroxybenzylamine (DHBA); (F) electrode potential, $+0.72 \mathrm{~V}$ vs. $\mathrm{Ag} / \mathrm{AgCl}$ reference electrode; $\mathrm{G}$, recorder sensitivity, $1 \mathrm{~V}, 10 \mathrm{nA} ; \mathrm{H}$, recorder rate, $30 \mathrm{~cm} / \mathrm{h}$. 
results are expressed as mean values \pm the standard error of the means. Statistical significance was determined by the use of Student's $t$-test and $P$ values are given in parentheses [6].

\section{RESULTS}

\section{Cochlear norepinephrine content}

When the cochlear tissues of the various animals were analyzed, only norepinephrine was detected. A typical chromatogram of norepinephrine measured in the cochleas of albino rats is illustrated in Fig. 2. The highest norepinephrine content was found in cochleas from hooded (pigmented) rats $(82.6 \pm 5.0 \mathrm{pg} / \mathrm{mg}$ tissue wet wt., $n=8)$ and the lowest was found in the cochleas of the cat $(3.8 \pm 0.4 \mathrm{pg} / \mathrm{mg}$ tissue wet wt., $n=3)$ (Fig. 3). The norepinephrine content of cochleas from the pigmented rats $(82.6 \pm 5.0 \mathrm{pg}$ / $\mathrm{mg}$ tissue wet wt., $n=8)$ was more than twice that of cochleas from albino rats $(34.1 \pm$ $4.5 \mathrm{pg} / \mathrm{mg}$ tissue wet wt., $n=7, P<0.0005)$. In addition, the cochlear norepinephrine content of pigmented guinea pigs $(40.2 \pm 4.7 \mathrm{pg} / \mathrm{mg}$ tissue wet wt., $n=4)$ was more than

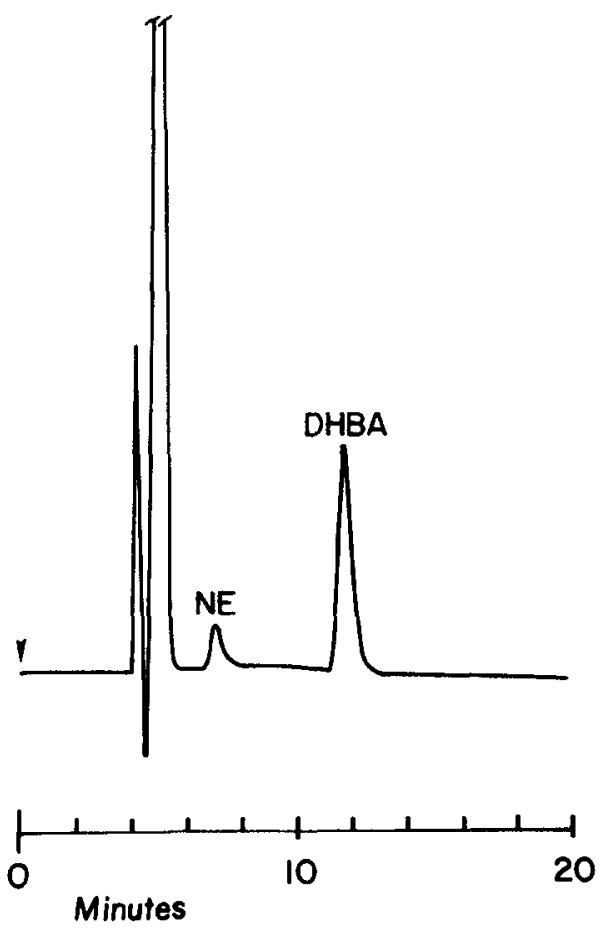

Fig. 2. Representative chromatogram of norepinephrine measured in a pooled sample of cochlear tissues from 3 albino rats. The chromatographic conditions were: A, stationary phase, $30 \mathrm{~cm} \times 3.9 \mathrm{~mm}$ i.d. $\mu$ Bondapak $C_{18}$ (Waters Assoc.); $B$, mobile phase, citric acid/phosphate eluant as described in text; $C$, flow rate, $0.8 \mathrm{ml} / \mathrm{min} ; \mathrm{D}$, temperature, ambient; $\mathrm{E}$, amount injected: $20 \mu \mathrm{l}$ of a pooled cochlear sample of 3 albino rats; $\mathrm{F}$, electrode potential, $+0.72 \mathrm{~V}$ vs. $\mathrm{Ag} / \mathrm{AgCl}$ reference electrode; $\mathrm{G}$, recorder sensitivity, $1 \mathrm{~V}, 20 \mathrm{nA} ; \mathrm{H}$, recorder rate, $30 \mathrm{~cm} / \mathrm{h}$. 


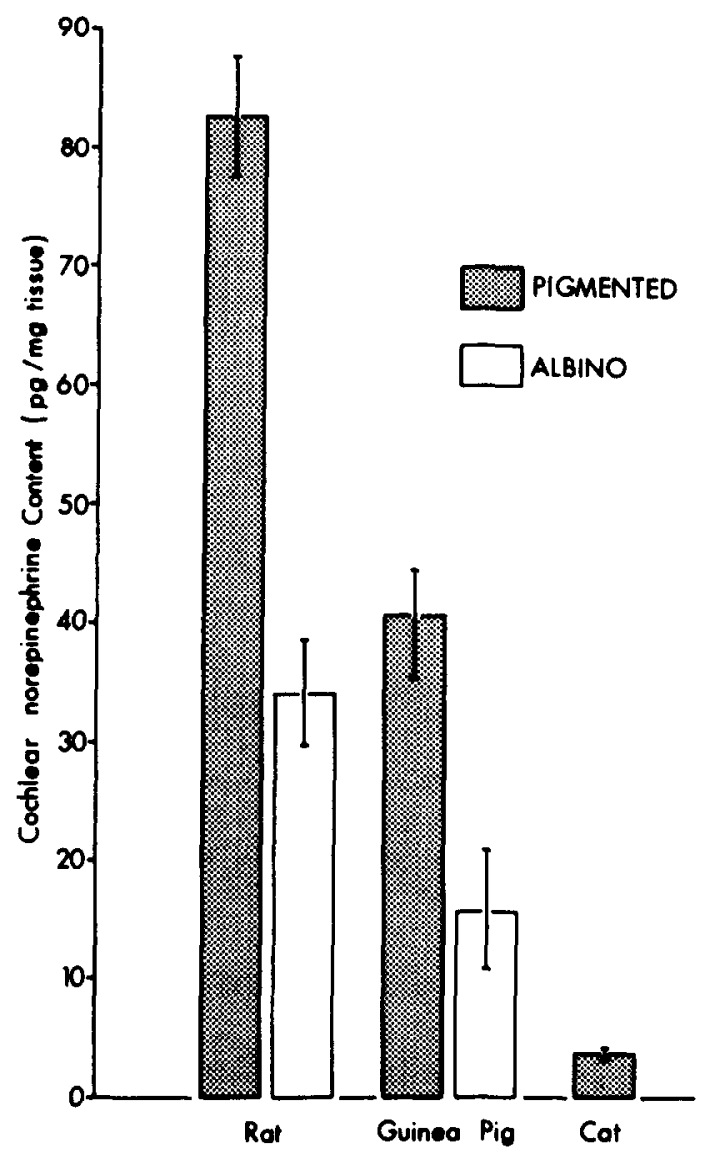

Fig. 3. Histograms of endogenous levels of norepinephrine measured in the cochleas of the albino rat, hooded rat, albino guinea pig, pigmented guinea pig and pigmented cat. Statistically significant differences occurred between the cochleas of albino and hooded rats $(P<0.0005)$ and the cochleas of the albino and pigmented guinea pigs $(P<0.01)$. Each bar represents the mean value of norepinephrine present, and the vertical lines represent the standard errors.

double that found in the cochleas of non-pigmented guinea pigs $(15.7 \pm 5.1 \mathrm{pg} / \mathrm{mg}$ tissue wet wt., $n=3, P<0.01$ ).

Norepinephrine content of the albino rat cochlea after either the extirpation of the superior cervical ganglion or the administration of reserpine

The norepinephrine content of albino rat cochleas was $24.7 \pm 5.1 \mathrm{pg} / \mathrm{mg}$ tissue wet wt. $(n=6) 48 \mathrm{~h}$ after a unilateral ganglionectomy. When the norepinephrine content of denervated rat cochleas was compared to that of controls $(34.1 \pm 4.5 \mathrm{pg} / \mathrm{mg}$ tissue wet wt.), no statistically significant difference was demonstrated. Only a $28 \%$ depletion of

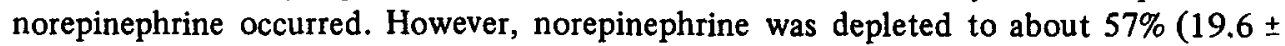
$2.6 \mathrm{pg} / \mathrm{mg}$ tissue wet wt., $n=3, P<0.05$ ) of normal $12 \mathrm{~h}$ after the administration of reserpine (Fig. 4). 


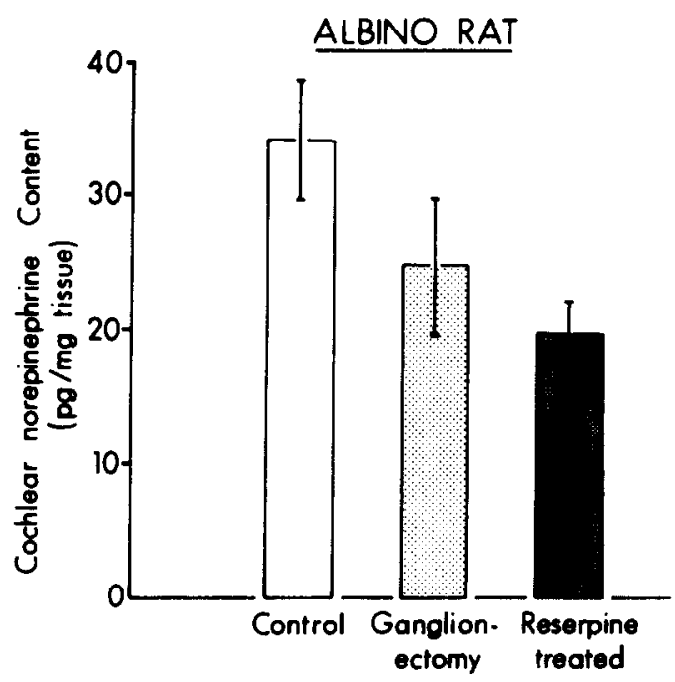

Fig. 4. Histograms comparing the effects of reserpine and of a surgical sympathectomy on norepinephrine content of albino rat cochleas. There was no statistical difference between the normal endogenous norepinephrine content of the rat cochlea and that present $48 \mathrm{~h}$ after a superior cervical ganglionectomy. There was a statistical difference in norepinephrine content of the rat cochlea $12 \mathrm{~h}$ after i.p. injection of reserpine $(P<0.05)$. Each histogram represents the mean value of norepinephrine, while the vertical lines represent the standard errors.

\section{DISCUSSION}

Picogram quantities of norepinephrine were conclusively identified and measured in the cochleas of treated and non-treated animals by high-performance liquid chromatography and electrochemical detection. No other catecholamines or serotonin were detected. The highest cochlear norepinephrine content was found in the pigmented rat $(82.6 \pm 5.0$ $\mathrm{pg} / \mathrm{mg}$ tissue wet wt.) and the lowest was in the cat $(3.8 \pm 0.4 \mathrm{pg} / \mathrm{mg}$ tissue wet wt.). It is not unusual for large variations to occur between species in the catecholamine content of any given tissue or organ. For example, the norepinephrine content of the superior cervical ganglion, which supplies the noradrenergic innervation of the inner ear, is 5- to 8-fold greater in the rat than in the cat [11]. Thus, the variations among species observed in this present study would not be unexpected. However, the variation between pigmented and non-pigmented animals of a single species suggests that the density of melanin-containing cells might be related to catecholamine content. For example, when pigmented and nonpigmented rats were compared, the pigmented rats had approximately a two-fold greater cochlear norepinephrine content than the albino rats $(P<0.0005)$.

The norepinephrine in the rat cochlea appears to be in part outside of noradrenergic neurons. Cochlear norepinephrine content of the albino rats was only partially depleted $48 \mathrm{~h}$ after superior cervical ganglionectomy and only partially depleted $12 \mathrm{~h}$ after administration of reserpine $(5 \mathrm{mg} / \mathrm{kg})$. Since it has been established that catecholamines are depleted almust cumpletely from neuronal tissues $48 \mathrm{~h}$ after a superior cervical ganglionectomy [22,23] or by $4 \mathrm{~h}$ after a $5 \mathrm{mg} / \mathrm{kg}$ dose of reserpine [3], the results of this 
investigation raise the possibility that cochlear norepinephrine is not confined totally to noradrenergic nerve terminals as previously assumed $[20,22,23]$. It is possible that picogram quantities of cochlear norepinephrine we have identified might not have been detected in previous studies because of limitations in the range of sensitivity of the fluorescence histochemical method. It has been suggested that the level of sensitivity of fluorescence histochemistry is not sufficient to detect small quantities of catecholamines. For example, although fluorescing granules of catecholamine were absent in atrial tissues of guinea pigs after the administration of reserpine, the atrial tissues were still responsive to noradrenergic nerve stimulation. Moreover, granular vesicles, indicative of norepinephrine, were observed in these atrial tissues when examined by electron microscopy [24,25].

The precise location of the non-neuronal norepinephrine in the cochlear tissues of the albino rats cannot be resolved by the present method. However, the observation that the cochleas of pigmented species contained more norepinephrine than corresponding albinos suggests that melanin granules of melanocytes might represent sites of binding for norepinephrine as previously proposed by Lindquist [14]. The presence of melanin is presumably the only anatomical difference between the cochlear tissues of pigmented and non-pigmented animals of a given species. Melanin granules are the result of the biological formation of cytoplasmic melanosomes and the enzymatic oxidation of tyrosine [19]. Melanosomes serve as sites where tyrosine is oxidized and the oxidative products are subsequently polymerized into the insoluble pigment, melanin.

Granules of melanin have been observed in the cochlear tissues of pigmented animals and man since the time of Corti $[2,13,18,28]$. These have been observed in various stages of formation in the cytoplasm of melanocytes which are intimately positioned along the cochlear vasculature in regions involved in the secretion, maintenance and absorption of endolymph and perilymph $[10,13]$. Interestingly, melanocytes develop from cells of the neural crest as do neurons of the sympathetic nervous system [27]. Thus, cochlear melanocytes might be more closely associated functionally with cochlear noradrenergic neurons than previously assumed. Work is currently underway to more precisely determine the localization of the non-neuronal norepinephrine in the cochlear membranous labyrinth.

\section{ACKNOWLEDGMENT}

This research was supported by National Research Service Award IF32NS06161 NEUB and Public Health Service Grant NS 13428.

\section{REFERENCES}

[1] Cherubino, M., Bonaccorsi, P. and Galioto, C.B. (1967): Intravital and morphological researches on a possible enzymatic and vasomotor action of melanocytes of the capillary bed of the inner ear. Bibl. Anat. 9, 126-130.

[2] Corti, A. (1851): Recherches sur l'organe de l'ouie des mammifères. Ztschr. wissensch. Zool. 3, 109.

[3] Carisson, A., Rosengren, E., Bertler, A. and Nilsson, J. (1957): Effect of reserpine on the metabolism of catecholamines. In: Psychotropic Drugs, pp. 363-372. Editors: S. Garattini and V. Ghetti. Elsevier, Amsterdam. 
[4] Densert, O. (1974): Adrenergic innervation in the rabbit cochlea. Acta Otolaryngol. 78, 345356.

[5] Felice, L.J., Felice, J.D. and Kissinger, P.T. (1978): Determination of catecholamines in rat brain parts by reverse-phase ion-pair liquid chromatography. J. Neurochem. 31, 1461-1465.

[6] Fischer, R.A. (1950): The Design of Experiments, 11 th Edn. Oliver and Boyd, Edinburgh.

[7] Hawkins, J.E. Jr. (1968): Vascular patterns of the membranous labyrinth. In: Third Symposium on The Role of Vestibular Organs in the Exploration of Space, pp. 241-257. National Aeronautics and Space Administration, Washington, D.C.

[8] Hilding, D.A. (1964): Catecholamine activity in the inner ear: histochemical study by electron microscopy. J. Acoust. Soc. Am. 36, 1016 (Abstract).

[9] Hilding, D.A. (1965): Cochlear chromaffin cells. Laryngoscope 75, 1-15.

[10] Hilding, D.A. and Ginzberg, R.D. (1977): Pigmentation of the stria vascularis. Acta Otolaryngol. 84, 24-37.

[11] Holzbauer, M. and Sharman, D.F. (1972): The distribution of catecholamines in vertebrates. In: Catecholamines. Handbook of Experimental Pharmacology, Vol. XXXIII, pp. 110-185. Editors: H. Blaschko and E. Muscholl. Springer-Verlag, Berlin.

[12] Keller, R., Oke, A., Mefford, 1. and Adams, R.N. (1976): Liquid chromatographic analysis of catecholamines. Routine assays for regional brain mapping. Life Sci. 19, 995-1004.

[13] LeFerriere, K.A., Arenberg, I.K., Hawkins, J.E. Jr. and Johnsson, L.-G. (1974): Melanocytes of the vestibular labyrinth and their relationship to the microvasculature. Ann. Otol. Rhinol. Laryngol. 83, 685-694.

[14] Lindquist, N.G. (1973): Accumulation of drugs in melanin. Acta Radiol. Diag. Suppl. 325, 1-92.

[15] Ross, M.D. (1969): Orange fluorescence in the acoustic nerve. J. Histochem. Cytochem. 17, 814-820.

[16] Ross, M.D. (1971): Fluorescence and electron microscopic observations of the general visceral efferent innervation of the inner ear. Acta Otolaryngol. Suppl. 286, 1-18.

[17] Ross, M.D. (1973): Autonomic components of the VIIIth nerve. Adv. Oto-Rhino-Laryngol. $20,316-336$.

[18] Savin, C. (1965): The blood vessels and pigmentary cells of the inner ear. Ann. Otol. Rhinol. Laryngol. 74, 611-623.

[19] Seiji, M. (1967): Melanogenesis. In: Ultrastructure of Normal and Abnormal Skin, pp. 183-201. Editor: A.S. Zelickson. Lea and Febiger, Philadelphia.

[20] Spoendlin, H. and Lichtensteiger, W. (1966): The adrenergic innervation of the labyrinth. Acta Otolaryngol. 61, 423-434.

[21] Spoendlin, H. and Lichtensteiger, W. (1967): The sympathetic nerve supply to the inner ear. Arch. Klin. Exp. Ohren-, Nasen- und Kehlkopfheilk. 189, 346-359.

[22] Terayama, Y., Holz, E. and Beck, C. (1966): Adrenergic innervation of the cochlea. Ann. Otol. Rhinol. Laryngol. 75, 69--86.

[23] Terayama, Y., Yamamoto, K. and Sakamoto, T. (1968): Electron microscopic observations on the postganglionic sympathetic fibers in the guinea pig cochlea. Ann. Otol. Rhinol. Laryngol. 77, $1152-1170$.

[24] Van Orden, L.S. III, Burke, J.P., Geyer, M. and Lodoen, F.V. (1971): Localization of depletionsensitive and depletion-resistant norepinephrine storage sites in autonomic ganglia. J. Pharmacol. Exp. Ther. 174, 56-71.

[25] Van Orden, L.S. III, Schaefer, J.M., Antonaccio, M.J. and Smith, C.B. (1974): Fine structural identification of a reserpine-resistant norepinephrine store in adrenergic nerve terminals in guinea pig atria. J. Pharmacol. Exp. Therap. 188, 668-675.

[26] Vinnikov, J.A., Govyrin, V.A., Leontieva, G.R. and Anichin, V.F. (1966): The adrenergic innervation of the organ of Corti. Dokl. Akad. Nauk. S.S.S.R. 171, 484.

[27] Weston, J.A. (1970): Migration and differentiation of neural crest cells. Adv. Morphogenesis 8, $41-114$.

[28] Wolff, D. (1931): Melanin in the inner ear. Arch. Otolaryngol. 14, 195-211. 